\title{
CLINICOHEMATOLOGICAL, IMMUNOPHENOTYPING, MOLECULAR PROFILE, AND OVERALL SURVIVAL IMPACT IN ACUTE LYMPHOID LEUKEMIA PATIENTS FROM NORTH INDIA
}

\author{
MANOJ KUMAR ${ }^{1,2 *}$, MOHIT CHOWDHRY ${ }^{1}$, RAJ NATH MAKRO0 ${ }^{1}$, DEEPIKA RANI ${ }^{1}$, VANDANA SHARMA ${ }^{1}$, \\ PANKAJ SHARMA ${ }^{2}$
}

${ }^{1}$ Department of Molecular Biology and Transplant Immunology, Indraprastha Apollo Hospitals, New Delhi, India. ${ }^{2}$ Laboratory of Oxidative Stress and Cancer Biology, Centre for Medical Biotechnology, Amity Institute of Biotechnology, Amity University, Noida, Uttar Pradesh, India.Email: manoj_m@apollohospitalsdelhi.com

Received: 03 June 2019, Revised and Accepted: 16 July 2019

\begin{abstract}
Objective: Cytogenetic plays an inevitable role in predicting the diagnosis of acute leukemia. The recurrent chromosomal aberrations in acute leukemia have provided critical insights into the pathophysiological mechanism of leukemogenesis. Cytogenetics findings at diagnostics provide important information for decision-making in both childhood and adult acute lymphoblastic leukemia (ALL). The cure rate for ALL is $>80 \%$ in children and 35\% in adults. Despite the therapeutic advances in ALL, several important biological and pathophysiological questions remain to be answered to achieve an accurate diagnosis, timely prognosis, and maximum therapeutic benefit.
\end{abstract}

Methods: The present study was carried out at tertiary care hospital, New Delhi, India. A total of 144 newly diagnosed ALL patients were analyzed for clinicohematological profile, immunophenotyping, conventional, and molecular cytogenetics.

Results: The study population was found to have normal karyotypes in most of the cases; however, abnormalities also reported. Our study clearly indicates that the application of fluorescence in situ hybridization has increased sensitivity and accuracy for detecting various chromosomal abnormalities, more so with the cryptic rearrangements.

Conclusion: We observed that the prevalence of the molecular subgroup of leukemia with a potential for a favorable clinical outcome (ETV6-RUNX1 and hyperdiploidy) in precursor B-ALL is higher in the North India.

Keywords: Cytogenetics, Chromosomal aberrations, Acute lymphoblastic leukemia.

(C) 2019 The Authors. Published by Innovare Academic Sciences Pvt Ltd. This is an open access article under the CC BY license (http://creativecommons. org/licenses/by/4. 0/) DOI: http://dx.doi.org/10.22159/ajpcr.2019.v12i9.34312

\section{INTRODUCTION}

Acute leukemia is characterized by the uncontrolled multiplication of undifferentiated hematopoietic precursors in blood, bone marrow, and lymphoid organs. It can originate from myeloid (acute myeloid leukemia [AML]) or lymphoid (acute lymphoid leukemia [ALL]) progenitor cells, with the latter having either T-cell or B-cell lineage origins (T-ALL or B-ALL). ALL is a neoplastic disease that results from a somatic mutation in a single lymphoid progenitor cell at one of the several discrete stages of development. In leukemia, an inframe fusion gene is formed which results in a protein with altered properties. ALL is the most common malignancy in children [1]. It accounts for $25 \%$ of all childhood cancers and approximately $75 \%$ of all cases of childhood leukemia [2].

The cure rate for ALL is $>80 \%$ in children and approximately $35 \%$ in adults. Remarkable advances have been made over the past 15 years in the treatment of ALL, and the understanding of its pathophysiology and several important biomarkers have been established.

Pediatric ALL is often cited as one of the true success stories of modern medicine. The cure rates have improved from virtually zero, before the advent of modern chemotherapy and radiotherapy (in the 1950s), to the current overall event-free survival rates of approximately $80 \%$ [2]. This success and exemplary progress is largely due to the identification of various biomarkers responsible for good and poor prognosis, diagnosis, and improvement in the understanding of how to combine and use the chemotherapeutic agents effectively with minimum toxicity in supportive care.
Despite advances in the treatment, $20-30 \%$ of children with ALL in whom remission is achieved after initial induction chemotherapy, subsequently relapse. An array of clinical and lymphoblastic biological features have been identified as prognostically significant in childhood ALL, including age, presenting leukocyte count, immunophenotype, chromosomal abnormalities, the presence of overt central nervous system leukemia, and the rapidity with which the patients demonstrate a response to initial induction chemotherapy [3].

\section{METHODS}

\section{Study design}

The study was conducted at the Department of Molecular Biology and Transplant Immunology, Indraprastha Apollo Hospitals, New Delhi. A total of 144 newly diagnosed ALL patients were included in the study with their written informed consent. The clinics and other details were taken (Table 1). These patients were further classified on the basis of risk stratification, i.e., low-risk and high-risk patients on the basis of age, sex, platelets, and WBC count at the time of diagnosis as per the criteria of the National Cancer Institute, USA (Table 2). Immunophenotyping was done to further categorize these patients. Karyotyping was done as a routine investigation in the patients. Fluorescence in situ hybridization (FISH) was performed on Pre B-ALL patients wherever possible. Five years survival analysis was also done in follow-up patient (Fig. 1a).

\section{Cytogenetics studies and karyotype analysis}

Heparinized bone marrow samples obtained the time of diagnosis were processed and cultured for $24 \mathrm{~h} / 48 \mathrm{~h}$ in RPMI 1640 medium (Caisson Labs, cat. no. RPMI-012P) and 20\% fetal bovine serum is 
Table 1: Clinical characteristics of the study patients

\begin{tabular}{ll}
\hline Total patients (n) & $\mathbf{1 4 4}$ \\
\hline Male (\%) & $112(78.1)$ \\
Female (\%) & $32(21.9)$ \\
Sex ratio & $3.5: 1$ \\
Age (\%) & \\
$0-5$ years & $57(38.6)$ \\
$5-10$ years & $51(36)$ \\
$10-16$ years & $36(26)$ \\
TLC (\%) & \\
$<4000 / \mathrm{mm}^{3}$ & $55(33.3)$ \\
$4000-20000 / \mathrm{mm}^{3}$ & $35(24.6)$ \\
$20000-50000 / \mathrm{mm}^{3}$ & $26(18.4)$ \\
$>50000 / \mathrm{mm}^{3}$ & $28(23.7)$ \\
Platelet count $(\%)$ & $26(18.4)$ \\
$<30.0 \times 10^{9} / \mathrm{L}$ & $72(50)$ \\
$30.0-50.0 \times 10^{9} / \mathrm{L}$ & $46(31.6)$ \\
$>50 \times 10^{9} / \mathrm{L}$ & \\
Immunophenotype (\%) & $128(88.6)$ \\
Pre B-ALL & $2(1.7)$ \\
B-ALL & $14(9.7)$ \\
T-ALL & \\
\hline B-ALL: B-cell acute lymphoblastic leukemia, T-ALL: T cell acute lymphoblastic \\
leukemia TLC: Total leukocyte count
\end{tabular}

leukemia, TLC: Total leukocyte count

Table 2: Risk stratification of patients at the time of diagnosis as per NCI criteria

\begin{tabular}{lllll}
\hline $\begin{array}{l}\text { Risk } \\
\text { group }\end{array}$ & Sex/n & $\begin{array}{l}\text { Age (Years) } \\
{[\mathbf{n}]}\end{array}$ & $\begin{array}{l}\text { TLC }\left(/ \mathbf{M m}^{3}\right) \\
{[\mathbf{n}]}\end{array}$ & $\begin{array}{l}\text { Platelets(/L) } \\
{[\mathbf{n}]}\end{array}$ \\
\hline $\begin{array}{l}\text { Low } \\
\text { risk }\end{array}$ & Females/32 & $0-9[108]$ & $\leq 50,000[116]$ & $\leq 50 \times 10^{9}[98]$ \\
$\begin{array}{l}\text { High } \\
\text { risk }\end{array}$ & Males $/ 112$ & $10-18[36]$ & $>50,000[28]$ & $>50 \times 10^{9}[46]$ \\
\hline
\end{tabular}

Risk stratification among patients on the basis of age, sex, TLC, and platelet counts. TLC: Total leukocyte count

added (GIBCO cat. no. 10270), COLCEMID (0.05 $\mu \mathrm{g} / \mathrm{ml})$ (Biological Industries $10 \mu \mathrm{g} / \mathrm{ml}$ cat. no. 12004-1D) was added for the past $60 \mathrm{~min}$ of culture, followed by hypotonic treatment with a $0.075-\mathrm{KCl}$ solution and a final fixation in methanol/acetic acid (3:1). Chromosomes were G-banded for identification whenever possible, at least, 20 metaphases were analyzed according to the International System for Cytogenetic Human Nomenclature, 2016.

\section{FISH}

FISH is a technique that involves the precise annealing of a singlestranded fluorescently labeled DNA probe to the complementary target sequences. The hybridization of the probe with the cellular DNA site is visible by direct detection using fluorescence microscopy. The interphase cells obtained from bone marrow specimens are processed with a hypotonic treatment with $0.075 \mathrm{M} \mathrm{KCl}$ followed by fixation in Carnoy's fixative (3 methanol:1 acetic acid). FISH was carried out by standard protocols and hybridization procedure was modified according to the probe manufacturer (Vysis-Abbott Molecular Abbott Park, Illinois, USA). Following hybridization excess and unbound probe were removed by the series of washes as recommended in the protocol. Finally, chromosome and nuclei were counterstained with DNA specific stain DAPI (4,6 diamidino-2-phenylindole) that fluoresces blue.

The following probes were used for FISH analysis

a. Dual-Color, Single-Fusion, Extra Signal Probes: ETV6/RUNX1 gene: The FISH assay for the cryptic 12; 21 translocations (ETV6/RUNX1 or, historically, TEL/AML1) has applications in the diagnosis and monitoring of ALL. The 12; 21 cryptic translocation cannot be seen on G-banded metaphases; therefore, FISH and other molecular methods are needed to detect this rearrangement. In a normal nucleus, the expected pattern for a cell hybridized with the LSI TEL/AML1 ES Dual
Color Translocation probe is the two orange (AML1), two green (TEL) (202G) signal pattern. An abnormal cell with the translocation would show the ETV6/RUNX1 fusion as yellow (red + green on the derivative chromosome 21), one green signal (uninvolved chromosome 12), and one large red signal (uninvolved chromosome 21).

b. Dual-Color, Dual-Fusion Probes: BCR/ABL1 gene: The dual-color, dual-fusion $B C R$ (green)/ABL1 (red) probe set allows for detection of all forms of the $B C R / A B L 1$ fusion (yellow), i.e., $\mathrm{t}(9 ; 22)$, variant translocations, and cryptic translocations or insertions. In a normal nucleus, the expected pattern is two orange, two green $(202 \mathrm{G})$ signal pattern. In a nucleus containing a balanced $t(9 ; 22)$, one orange, one green signal, and two orange/green (yellow) fusion signals are observed (101G2F).

c. Dual-Color, Break-Apart Probe: MLL gene: Structural rearrangements of the mixed-lineage leukemia (MLL) gene at 11q23 are welldocumented recurring abnormalities and are observed in ALL. The majority of $M L L$ rearrangements occur as a result of an established chromosomal translocation involving 11q23. The probe is a dualcolor break-apart probe made of differentially labeled (red and green) DNA segments located on either side of the MLL breakpoint cluster region. The separation of red and green signals indicates $M L L$ break for the 3' and 5' regions of the gene. The advantage of this kind of FISH assessment is that it can detect all recurrent and possibly novel $M L L$ rearrangements in a single experiment.

Survival analysis

Analysis of disease outcome was examined as overall survival (OS). The OS was measured from the date of initial diagnosis of ALL to the date of death from any cause or date of the last contact using the Kaplan-Meier method which is a nonparametric (actuarial) technique for estimating time-related events (the survivorship function) (Fig. 1a).

\section{RESULTS}

The clinical and laboratory features of pediatrics ALL patients at diagnosis are summarized in Table 1 . The age of the study subjects varied between 1.5 and 15.8 years. The mean and the median age were $7.2( \pm 4.1)$ and 6.5 years, respectively. The gender distribution of the study subjects revealed that there were 112 male (78.1\%) and 32 female (21.9\%). The total leukocyte count (TLC) of the patients at the time of diagnosis ranged between 600 and 7 lakhs/cumm. The mean and the median TLC were $39000 /$ cumm and $8300 /$ cumm, respectively. The TLC was $<4000,4000-20,000,20,000-50,000$, and $>50,000$ in $55(33.3 \%)$, $35(24.6 \%), 26(18.4 \%)$, and $28(23.7 \%)$ patients, respectively. The platelet count of the patients at the time of diagnosis was $<30.0 \times 10^{9} / \mathrm{L}$ in $26(18.4 \%)$ patients, $30.0 \times 10^{9} / \mathrm{L}-50.0 \times 10^{9} / \mathrm{L}$ in $72(50 \%)$ patients, and more than $50 \times 10^{9} / \mathrm{L}$ in $46(31.6 \%)$ patients. The immunophenotyping results revealed Pre B ALL profile in 128 (88.6\%), B cell ALL in 2 (1.7\%), and T cell ALL in $14(9.7 \%)$ patients.

\section{Karyotype analysis (Fig. 1b)}

Out of the 144 patients, karyotype results were available in 131 (91\%) patients and poor morphology in the remaining $13(9 \%)$ patients. These patients were further divided according to cytogenetics abnormalities, i.e., numerical chromosome abnormalities (ploidy status) and structural abnormalities.

On the basis of ploidy, the patients were divided as diploid in 91(69.46\%) patients; pseudodiploidy in $15(11.45 \%)$ patients; hyperdiploidy (>47-92 chromosome) in $15(11.45 \%)$ patients, hyperdiploidy with additional change in $3(2.29 \%)$ patients, hypodiploidy $(<46$ chromosome) in 4 (3.05\%) patients, and hypodiploidy with additional change in $3(2.29 \%)$ patients. Trisomy of 21 chromosomes was seen in 8 patients and trisomy of chromosome 8 was seen in 4 patients. Other trisomies observed, including those of sex chromosome and their frequencies are depicted in Table 3.

Thirty-five $(26.7 \%)$ structural abnormalities were observed in group of patients that included $9(25.7 \%)$ translocations, $2(5.71 \%)$ inversions, 11 (31.42\%) deletions, 2 (5.71\%) isochromosome, 


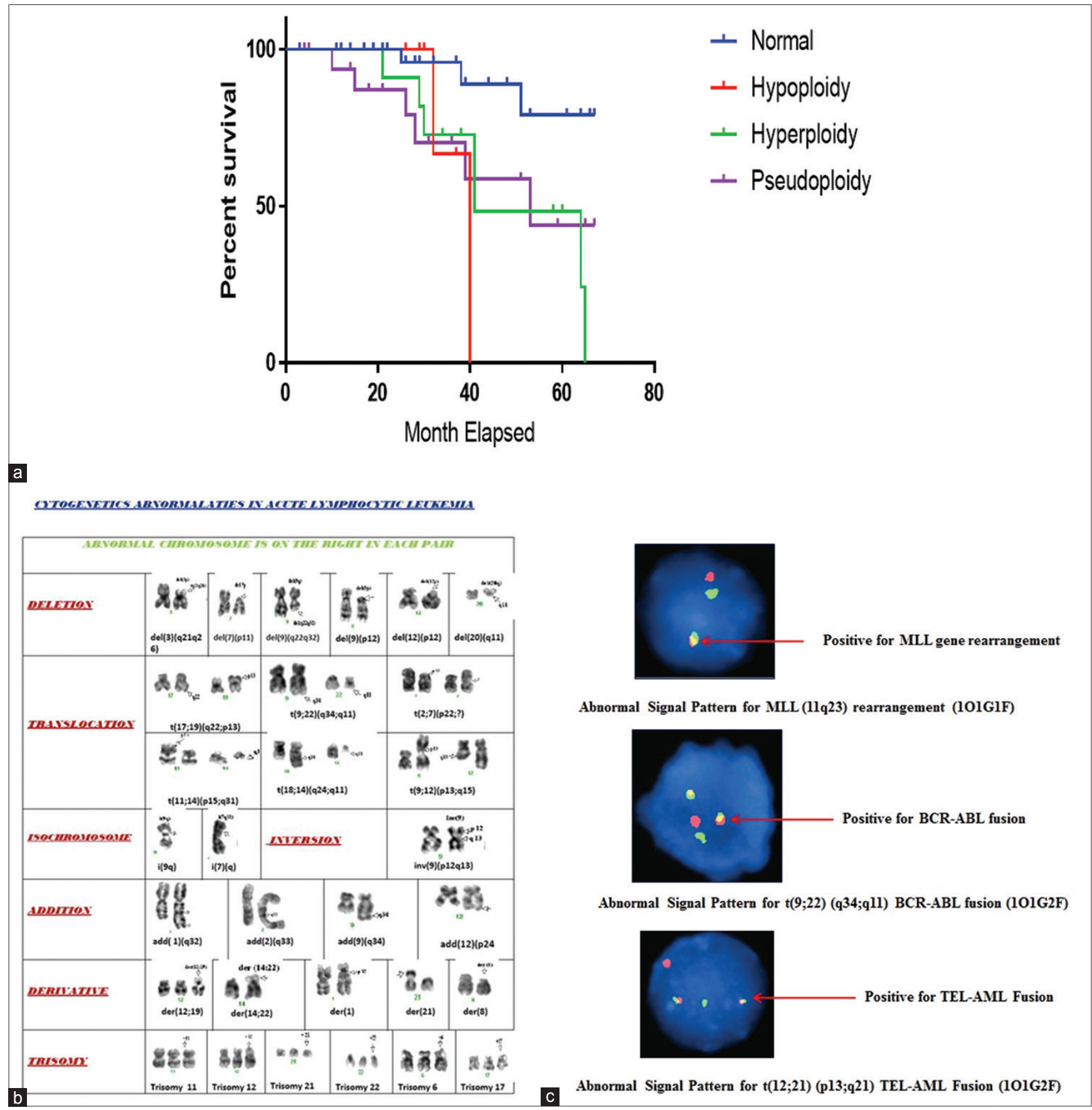

Fig. 1: (a) Correlation of karyotypic abnormalities with overall survival of acute lymphoblastic leukemia patient by Kaplan-Meier curve. (b) Chromosomal abnormalities observed in acute lymphoblastic leukemia patients. (c) Abnormalities observed in FISH in acute lymphoblastic leukemia patients

$1(2.85 \%)$ duplication, $2(5.71 \%)$ additions, and 8 (22.8\%) derivative chromosomes.

Among the translocations, the most common translocation was $\mathrm{t}(9 ; 22)$ in $5(14.28 \%)$ patients. Deletions of chromosome 5, 7, and 9 were the most common deletions observed (Table 3).

\section{Karyotype and fish analysis}

For 30 pre-B-ALL patients, it was possible to perform both karyotype and FISH panel for all three probes, namely, TEL/AML1 t(12:21) (p13-q22), BCR-ABL t $(9 ; 22)$ and $M L L$, as per the clinicians' choice.

Both karyotype and FISH analysis were negative for ETV6-RUNX1 gene in $17(56.66 \%)$ out of 30 patients (Tables 4 and 5). ETV6-RUNX1 gene fusion was positive in 13 (43.3\%) patients either by karyotype and/or by FISH analysis. Both karyotype and FISH analysis were positive for ETV6-RUNX1 gene in $8(26.66 \%)$ out of 30 patients. In addition, $4(13.33 \%)$ patients were found positive for ETV6-RUNX1 fusion gene by FISH analysis only, indicating cryptic translocation. Out of these, $13(43.33 \%)$ patients positive for ETV6-RUNX1 gene, variant signals (one fusion) were observed in $3(10 \%)$ patients. Hyperdiploidy was observed in $8(26.66 \%)$ ETV6-RUNX1 fusion gene-positive patients which involved ETV6 in 6 (75\%) patients and RUNX1 gene in 2 (25\%) patients (Fig. 1c)

For 30 patients, it was possible to perform both karyotype and FISH panel for $B C R-A B L$ gene. Both karyotype and FISH analysis were negative for $B C R-A B L$ gene in $25(83.33 \%)$ out of 30 patients. Both karyotype 
Table 3: Cytogenetic characteristics of patients

\begin{tabular}{|c|c|}
\hline Cytogenetic Findings & Number of cases $(\%)$ \\
\hline \multicolumn{2}{|l|}{ Ploidy status } \\
\hline Normal diploid & $91(69.46)$ \\
\hline Pseudodiploid & $15(11.45)$ \\
\hline Hyperdiploid & $15(11.45)$ \\
\hline Hyperdiploid with additional change & $3(2.29)$ \\
\hline Hypodiploid & $4(3.05)$ \\
\hline Hypodiploid with additional change & $3(2.29)$ \\
\hline Total & 131 \\
\hline \multicolumn{2}{|l|}{ Numerical changes } \\
\hline \multicolumn{2}{|l|}{ Trisomies } \\
\hline Chromosome 21 & $8(44.44)$ \\
\hline Chromosome 8 & $4(22.22)$ \\
\hline Chromosome 4, 5, 9, 12, 13, 17, 18, 22 & $3(16.66)$ \\
\hline Chromosome $3,6,7,11,14$ & $2(11.11)$ \\
\hline Chromosome 10, 15, 16, 19, X & $1(5.5)$ \\
\hline Total & 18 \\
\hline \multicolumn{2}{|l|}{ Monosomies } \\
\hline Chromosome 6, 8, 19 & $1(33.33)$ \\
\hline Chromosome 1, 7, 9, 10, 14, 16, 17, 22, Y & $2(66.66)$ \\
\hline Total & 3 \\
\hline \multicolumn{2}{|l|}{ Structural changes } \\
\hline $\begin{array}{l}\text { Translocation } \mathrm{t}(9 ; 22), \mathrm{t}(9: 12), \mathrm{t}(2 ; 7) \\
\mathrm{t}(11 ; 14), \mathrm{t}(2 ; 7), \mathrm{t}(18 ; 14), \mathrm{t}(17 ; 19)\end{array}$ & $9(25.71)$ \\
\hline Inversion; Inv9(p12q13) & $2(5.71)$ \\
\hline Deletion; del(7)(p12), del(7)(q32), del(5) & $11(31.42)$ \\
\hline \multicolumn{2}{|l|}{$(q 15), \operatorname{del}(9)(p 21), \operatorname{del}(9)(q 11), \operatorname{del}(7 p)$} \\
\hline \multicolumn{2}{|l|}{$(\mathrm{p} 12), \operatorname{del}(3)(\mathrm{q} 26), \operatorname{del}(20)(\mathrm{q} 11)$} \\
\hline Isochromosome; $\mathrm{i}(7 \mathrm{q}), \mathrm{i}(9 \mathrm{q})$ & $2(5.71)$ \\
\hline Duplication; dup1(q32q44) & $1(2.85)$ \\
\hline Addition; add(2q33), add(9q34) & $2(5.71)$ \\
\hline $\begin{array}{l}\text { Derivative; } \operatorname{der}(8), \operatorname{der}(9 ; 12), \operatorname{der}(1), \\
\operatorname{der}(21), \operatorname{der}(14: 22)\end{array}$ & $8(22.85)$ \\
\hline Total & 35 \\
\hline
\end{tabular}

Division of patients on the basis of ploidy status, numerical changes, and structural changes

and FISH analysis were positive for $B C R-A B L$ gene in $5(16.66 \%)$ out of 30 patients. Out of these five patients positive for $B C R-A B L$ fusion gene, variant signals (one fusion) were observed in 1 (20\%) patient. Hyperdiploidy was observed in $1(3.33 \%) B C R-A B L$ fusion gene-positive patient which involved the $B C R(9 \mathrm{q} 34)$ gene.

For 30 patients, it was possible to perform both karyotype and FISH panel for $M L L$ gene. Both karyotype and FISH analysis were negative for $M L L$ gene in $26(86.66 \%)$ out of 30 patients. MLL rearrangements were seen in $4(13.3 \%)$ patients either by karyotype and/or by FISH analysis. Both karyotype and FISH analysis were positive for $M L L$ gene in $2(50 \%)$ out of 30 patients. In addition, $2(50 \%)$ patients were positive for $M L L$ gene rearrangement in FISH analysis only, indicating cryptic rearrangement. Hyperdiploidy and hypodiploidy were observed in $1(3.33 \%)$ patient each of $M L L$ rearrangement.

\section{Survival analysis}

Out of 144 patients, five-year survival data available for 70 patients were analyzed using Prism 7 software. A patient diagnosed with hyperploid had better overall survival than patient with hypoploidy (Fig. 1a).

\section{DISCUSSION}

Acute leukemia is characterized by the uncontrolled clonal proliferation of hematopoietic precursor cells coupled with aberrant or arrested differentiation. ALL is the most common cancer diagnosed in children and represents $23 \%$ of cancer diagnoses among children younger than 15 years.

Numerous clinical and laboratory findings, including prognostic factors such as age, gender, cell count, pathophysiological, and cytogenetics at the time of diagnosis helps in determining the intensity and severity of disease and to predicts the best clinical outcome.

\section{Demographic and clinical findings}

In the present study, the age of the study subjects varied between 1.5 and 15.8 years with a mean and the median age of $7.2( \pm 4.1)$ and 6.5 years, respectively. Advani et al. [4] reported a median age of 8.8 years in their study. The majority of patients $(74.6 \%)$ in our study population were below 10 years of age indicating a younger study population. More so, a larger number of patients $(38.6 \%)$ were $<5$ years of age. Our results are concurrent with Advani et al. [4]. The authors reported $60 \%$ and $57 \%$ patients, respectively, aged between 2 and 9 years [5,6]. Further reports by Wessels et al. and Silverman et al. have also supported our findings [7,8].

The gender distribution of the study subjects revealed that there were 112 male $(78.1 \%)$ and 32 female $(21.9 \%)$ with a male to female ratio of 3.5:1. A male to female ratio of 2.9:1, 2.6:1, and 2.14:1 was reported previously [4]. This distorted sex ratio is not uncommon from studies in India [4-6].

In the laboratory findings, the TLC ranged between 600 and 7 lakhs/L. The mean and the median TLC were 39,000/cumm and 8300/cumm, respectively. A mean TLC of 38.8 and $62.7 \times 109 / \mathrm{L}$ in two different population from South Africa, respectively [8]. In contrast, Silverman et al. reported a mean WBC count of $9.8 \times 10^{9} / \mathrm{L}$ in 1255 patients [7]. In our study, the TLC was $>50.0 \times 10^{9} / \mathrm{L}$ in $28(23.7 \%)$ patients. In three separate studies, it was observed that $26-30.9 \%$ of their patients had TLC $>50.0 \times 10^{9} / \mathrm{L}$ [4-6]. These findings are in concordance with our observation. However, Shanta et al. had reported TLC $>60.0 \times 10^{9} / \mathrm{L}$ in $60 \%$ of patients in their series previously [9].

In the present study, hyperleukocytosis (defined as TLC $>100.0 \times 10^{9} / \mathrm{L}$ ) was found in $8(7.8 \%)$ patients. Studies from other Indian centers reported hyperleukocytosis in $15.3-23.2 \%$ cases $[6,10]$. Silverman et al. reported hyperleukocytosis in $10.8 \%$ of the ALL cases [7]. In our experience, the incidence of hyperleukocytosis was lower than the figures reported in other Indian centers and was similar to the prevalence reported from other nations. Children with TLC $>50,000$ were considered in the high-risk group.

\section{Cytogenetic analysis}

Mrozek et al. have described that the standard cytogenetic analysis can be obtained in most of the patients with ALL [11]. In large studies of adult ALL, between $70 \%$ and $75 \%$ of samples analyzed cytogenetically were deemed successful. Higher success rates, 83 and 91\%, were reported by two large studies of childhood ALL [12,13]. Among successfully analyzed patients, one or more clonal aberration has been detected in $57-82 \%$ of children with ALL $[12,13]$.

In our study, out of the 144 patients, successful karyotype results were available in 131 (91\%) patients and poor morphology in the remaining $13(9 \%)$ patients. Waghray et al. in their study reported successful karyotyping in $52 \%$ of the cases [14]. Similarly, in a study by Yang, karyotyping was possible in $86 \%$ of the patients [15]. In another study by Forestier et al., cytogenetic analyses were carried out in 1372 (66\%) patients. Among these, 787 (57\%) displayed clonal chromosomal abnormalities [16]. Perez-Vera et al. in a study including 150 Mexican children aged from 5 months to 16 years with ALL reported successful karyotyping in 131 (87\%) children [17]. These studies show that the successful karyotyping rate in our study was either comparable or better than most of the other studies. This could be due to stringent quality control and aseptic measures followed in our laboratory. Besides, most of the bone marrow samples received in the lab are from within the hospital and are transported in ambient temperature to the laboratory without any delay in time.

Whitlock and Gaynon have already explained in their study that both chromosome number (ploidy) and structural alterations have independent prognostic significance in childhood ALL [18]. 
Table 4: Comparison of karyotype and FISH analysis

\begin{tabular}{|c|c|c|c|c|c|}
\hline \multirow[t]{2}{*}{ S. No. } & \multirow[t]{2}{*}{ Clinical diagnosis } & \multirow[t]{2}{*}{ Karyotype } & \multicolumn{3}{|l|}{ FISH } \\
\hline & & & $T E L / A M L 1$ & $M L L$ & $B C R / A B L$ \\
\hline 1 & Pre B-ALL & $46, \mathrm{XX}$ & + & - & - \\
\hline 3 & Pre B-ALL & $46, \mathrm{XY},-7,+8, \mathrm{t}(9 ; 22)(\mathrm{q} 34 ; \mathrm{q} 11)$ & - & - & + \\
\hline 4 & Pre B-ALL & $46, \mathrm{XX}$ and $10 \%$ cells showing hyperdiploidy & + & - & - \\
\hline 5 & Pre B-ALL & $46, X Y, t(10 ; 14)(q 24 ; q 11)$ & - & - & - \\
\hline 6 & Pre B-ALL & $46, X Y, \operatorname{der}(1), \operatorname{del}(7 p)[18] / 46, X Y[2]$ & - & - & - \\
\hline 7 & Pre B-ALL & $46, \mathrm{XX}$ & + & - & - \\
\hline 8 & PRE B-ALL & $46, X Y, t(9: 22)(q 34 ; q 11)$ & - & - & + \\
\hline 9 & Pre B ALL & $46, X Y$ & - & - & - \\
\hline 10 & Pre B-ALL & $46, X Y$ & + & - & - \\
\hline 11 & Pre B-ALL & $46, X Y, 11$ q23 & - & + & - \\
\hline 12 & Pre B-ALL & 46, XY, t(9:22) (q34;q11), del (9p) & - & - & + \\
\hline 13 & Pre B-ALL & $46, x X, t(12 ; 21)(p 13 ; q 22)$ & + & - & - \\
\hline 14 & Pre B-ALL & $46, X X, t(12 ; 21)(\mathrm{p} 13 ; \mathrm{q} 22)$ & + & - & - \\
\hline 15 & Pre B-ALL & $46, X Y$ & - & + & - \\
\hline 17 & Pre B-ALL & $46, X Y, 11 q 23$ & - & + & - \\
\hline 18 & Pre B-ALL & $47, \mathrm{XY},+15, \mathrm{t}(12 ; 21)(\mathrm{p} 13 ; \mathrm{q} 22)$ & + & - & - \\
\hline 19 & Pre B-ALL & $46, X Y$ & - & + & - \\
\hline 20 & Pre B-ALL & $45, \mathrm{XX},-7, \mathrm{t}(9 ; 22)(\mathrm{q} 34 ; \mathrm{q} 11)$ & - & - & + \\
\hline 21 & Pre B-ALL & $46, X X, t(12 ; 21)(p 13 ; q 22)$ & + & - & - \\
\hline 22 & Pre B-ALL & $46, \mathrm{XY}$ & - & - & - \\
\hline 23 & Pre B-ALL & $46, X Y$ & - & - & - \\
\hline 24 & Pre B-ALL & $46, \mathrm{XY}, \mathrm{t}(12 ; 21)(\mathrm{p} 13 ; \mathrm{q} 22)$ & + & - & - \\
\hline 25 & Pre B-ALL & $92, \mathrm{XX}[4] / 46, \mathrm{XX}, \mathrm{t}(12 ; 21)(\mathrm{p} 13 ; \mathrm{q} 22)[11]$ & - & - & - \\
\hline 26 & Pre B-ALL & $\begin{array}{l}\text { 46, XY, t(12;21) (p13;q22 [2]/43 59, IDEM, }+4,+6,+9,+11,+13 \text {, } \\
+16,+18,+19,=20,+21,+22 \text {, [CP8], Hyperdiploidy in } 80 \% \text { cells }\end{array}$ & + & - & - \\
\hline 27 & Pre B-ALL & $47, \mathrm{XX},+\operatorname{mar}[3] / 46, \mathrm{XX}, \mathrm{t}(12 ; 21)(\mathrm{p} 13 ; \mathrm{q} 22),[22]$ & + & - & - \\
\hline 28 & Pre B-ALL & $\begin{array}{l}\text { 46, XY, t(12;21) (p13;q22) [2], 47 50, XY, +5, der (8), +11, +12. } \\
+13,[\mathrm{cp} 4]\end{array}$ & + & - & - \\
\hline 29 & Pre B-ALL & $48, \mathrm{XY},+9,+22, \mathrm{t}(9: 22)(\mathrm{q} 34 ; \mathrm{q} 11) \mathrm{x} 2$ & - & - & + \\
\hline 30 & Pre B-ALL & $46, \mathrm{XY}$ & - & - & - \\
\hline
\end{tabular}

Table 5: Summary of the FISH results for ETV6/RUNX1, BCR-ABL, and $M L L$ gene and its comparison with karyotyping result

\begin{tabular}{|c|c|c|c|c|c|c|}
\hline \multirow[t]{2}{*}{ Chromosome abnormalities } & \multicolumn{6}{|c|}{ Total number of patients (\%) } \\
\hline & $\begin{array}{l}\text { Negative by } \\
\text { karyotyping and } \\
\text { FISH }\end{array}$ & $\begin{array}{l}\text { Positive by } \\
\text { karyotyping and } \\
\text { FISH }\end{array}$ & Positive by FISH only & Variant & Hyperdiplody & Hypodiploidy \\
\hline $\mathrm{t}(12 ; 21)($ ETV6/RUNX1) $(\mathrm{n}=30)$ & $17(56.66)$ & $13(43.3)$ & $4(13.33)$ & $3(10)$ & $\begin{array}{l}8(26.66) \\
\text { ETV6-6 }(75 \%) \\
\text { RUNX1-2 (25\%) }\end{array}$ & \\
\hline $\mathrm{t}(9 ; 22) B C R / A B L 1$ fusion $(\mathrm{n}=30)$ & $25(83.33)$ & $5(16.66)$ & & $1(20)$ & $1(3.33)$ & \\
\hline Break-Apart $M L L$ gene $11 \mathrm{q} 23(\mathrm{n}=30)$ & $26(86.66)$ & $4(13.3)$ & $2(50)$ & 0 & $1(3.33)$ & $1(3.33)$ \\
\hline
\end{tabular}

In the present study, normal karyotype was observed in 91 (69.46\%) patients; pseudodiploid in 15 (11.45\%) patients; hyperdiploidy (>4792 chromosome) in $15(11.45 \%)$ patients, hyperdiploidy with additional change in $3(2.29 \%)$ patients, hypodiploidy ( $<46$ chromosome) in $4(3.05 \%)$ patients, and hypodiploidy with additional change in $3(3.05 \%)$ patients. Our findings are inconsistent with previous studies. Waghray et al. have reported that $31 \%$ of the patients had a normal karyotype with hyperdiploid karyotype in $38 \%$ of the patients [14]. Gladstone et al. found hypodiploidy in $63.3 \%$, pseudodiploidy in $20 \%$, and hyperdiploidy in $6 \%$ of patients [19]. In contrast to these studies, our study had a very high number of normal karyotype results, i.e., approximately $70 \%$ of patients.

The rate of hyperdiploidy in our study was $12.5 \%$, which included both hyperdiploidy with and without any additional change. Our findings were comparable to the study done by Amare et al. who had a hyperdiploidy rate of almost $15.4 \%$ [20]. In fact, in their study, they found a lower frequency of hyperdiploidy (15.4\%) and a higher frequency of hypodiploidy (38.4\%). Similarly, Li et al. have reported hyperdiploidy of more than 50 chromosomes in $17.5 \%$ of their children and $3.4 \%$ of their adults [21]. Pui et al., in 2008, have described that among all the chromosomal abnormalities identified in childhood ALL, hyperdiploidy $(2 n>50)$ was associated with the most favorable prognosis compared to other cytogenetic groups [10]. Arico et al. have established that the high hyperdiploidy $(2 n=51-65)$ generally occurs in cases with clinically favorable prognostic factors (patients aged 1-9 years with a low WBC count) and is itself an independent favorable prognostic factor [22].

A very useful explanation about the mechanism of gain or loss of chromosome has been described by Pederson-Biergaard and Rowley in 1994 [23]. They described that non-disjunction at mitosis may be the possible mechanism of gain or loss of a whole chromosome. The other mechanism which leads to extensive chromosome loss in the hypodiploid may be the development of a haploid karyotype with a 
gain of certain chromosomes or multiple losses by non-disjunction. In addition to non-disjunction, chromosome lagging, formation of micronuclei, deletion of parts of chromosomes or telomeric loss may also result in chromosome loss or gain of the chromosome. Onodera et al. have described that the hyperploid karyotype, which arises either by doubling of chromosomes from a near-haploid karyotype or gain of chromosomes from a diploid karyotype during a single abnormal cell division [24].

We reported $7(4.9 \%)$ cases of hypodiploidy with or without any additional changes. Our findings corroborate with literature which says that the hypodiploidy is observed in $3-10 \%$ of adults and $1-7 \%$ of childhood ALL [25]. Li et al. in their study found that $4.9 \%$ of children and $4 \%$ of adults showed hypodiploidy with $40-45$ chromosomes [21]. Pui et al. have described that a progressively worse outcome is associated with a decreasing chromosome number (hypodiploidy) [10]. Chessels et al. showed that patients with near haploidy (1\%), hypodiploidy (9\%), and low hyperdiploidy (16.5\%) had a relatively poor prognosis [12].

We observed thirty-five (26.7\%) structural abnormalities in our patients that included $9(25.7 \%)$ translocations, $2(5.71 \%)$ inversions, $11(31.42 \%)$ deletions, 2 (5.71\%) isochromosome, 1 (2.85\%) duplication, $2(5.71 \%)$ additions, and $8(22.8 \%)$ derivative chromosomes. Pui et al. have described that nearly half of childhood ALL have chromosomal abnormalities in the form of translocations, which are nearly equally divided between random and nonrandom rearrangements [26]. Among the translocations, we observed that the most common translocation was $t(9 ; 22)$ in $5(14.28 \%)$ patients. Padhi et al. in their study carried out on 31 subjects observed that translocations as their major structural abnormality [27]. The $t(9 ; 22)$ was observed in approximately $10 \%$ of their patients.

\section{Fish analysis}

FISH can be easily performed on specimens prepared for cytogenetic studies, is more sensitive, able to diagnose cryptic rearrangements, and provides rapid results. Application of FISH, therefore, represents an efficient and effective strategy to maximize the information obtained from clinical specimens. In our setting, as a routine, we usually perform karyotyping on all ALL samples and FISH for ETV6-RUNX1 fusion, $B C R-A B L$ and $M L L$ rearrangements for pre B-ALL patients.

The $\mathrm{t}(12 ; 21)$ (p13; q22) involving the RUNX1 (AML1 and CBFA2) gene is the most frequent translocation in children with ALL. This translocation is present in $25 \%$ of childhood precursor-BALL and $2 \%$ of adult precursor-B-ALL and is correlated with a moderate to favorable prognosis [28-30]. Although this translocation can be detected by both conventional karyotype and FISH, according to "Acute Lymphoblastic Leukemia Best Practice Guidelines (2011) V1. 00'6," it is mandatory to perform FISH testing for ETV6/RUNX1 in all infants and pediatric cases due to its cryptic nature and its prognostic significance. ETV6/RUNX1 probe, in addition to detecting cryptic $\mathrm{t}(12 ; 21)(\mathrm{p} 13 ; \mathrm{q} 22)$ translocation also detects: (i) Amplification of RUNX1 which signifies intrachromosomal amplification of chromosome 21 (iAMP21) and (ii) extra signals of RUNX1 which suggests hyperdiploid karyotype.

Interphase FISH testing for confirmation for high hyperdiploidy should be performed by including probes for chromosomes X, 4, $6,10,14,17$, and 18 especially in cases when a normal karyotype is obtained, and interphase FISH identifies extra signals for RUNX1 or where chromosome analysis is unsuccessful. The $t(12 ; 21)(p 13 ; q 22)$ (cryptic on karyotyping) in the production of a fusion protein that acts in a dominant-negative pattern and inhibits the transcription of RUNX1 gene. After the first detection of the ETV6-RUNX1 fusion by FISH, a large number of studies demonstrated that the $t(12 ; 21)$ is rarely the only abnormality present. Additional abnormalities include $\operatorname{del}(6 q)$, Del(11q), rearrangements of $12 p$, and $\operatorname{del}(16 q)$, and often these abnormalities provide a clue that a $\mathrm{t}(12 ; 21)$ might be present. The $t(12 ; 21)$ has a favorable prognosis with cure span in $\geq 90 \%$, especially if other favorable factors are present. The frequency of this translocation has been found in a range from $14 \%$ to $25 \%$ by molecular techniques [31]. In our study, we detected $t(12 ; 21)$ (p13;q22) with a frequency of $43.3 \%$ which included detection by either of the techniques. Therefore, we reported a higher incidence of ETV6/ RUNX1 involving B lineage ALL than previously reported studies in this region [32]. It is worth noting that the lower frequency of this fusion gene has also been observed in other studies from within India (6\%), Mexico (9.6\%), Argentina (11.6\%), Thailand (12\%), China (17.9\%), and Taiwan (19\%) [33-38]. The higher frequency of ETV6/RUNX1 gene along with hyperdiploidy provides a clue to the higher frequency of molecular subgroup of leukemia with a potential for favorable clinical outcome in precursor B-ALL from the North India. This is in complete contrast with the study done by Inamdar et al. from Bombay, and Padhi et al. from Southern India who found a very low frequency of B-ALL with favorable clinical outcome $[27,33]$. These geographical variations within India can be explained on the basis that the prevalence of this gene in the North Indian population per se could be more as compared to other parts of India. Furthermore, India is a big country has diverse social and cultural population, thereby bringing heterogeneity in the patient population as well. The difference in the patients' inclusion criteria could also be a reason for this high incidence.

For 30 patients, it was possible to perform both karyotype and FISH panel for BCR-ABL gene in our study. The Philadelphia (Ph) chromosome is derived from the $t(9 ; 22)$ ( $q 34 ; q 11.2)$. The incidence of $t(9 ; 22)$ in childhood ALL varies from $3 \%$ to $5 \%$, but various authors have reported its incidence ranging from $2 \%$ to $50 \%$ [39-43]. At the molecular level, the breakpoints in B-ALL and CML differ, and this variation leads to the production of p190 and p210 fusion proteins, respectively. In our study, both karyotype and FISH analysis were positive for BCR-ABL gene in $5(16.66 \%)$ out of 30 patients which is in concordance with the other studies [39-43].

Russo et al. found partial or complete monosomy seven in approximately $25 \%$ of 57 children with $\mathrm{Ph}+\mathrm{ALL}$ [44]. In our study, although the positivity rate of this fusion was low (5 patients, $16.66 \%$ ), we did observe monosomy seven in two out of 5 patients $(40 \%)$. This observation is notable because the loss of one copy of chromosome seven generally characterizes myeloproliferative disorders that progress to acute myeloid leukemia. This subgroup of children with $\mathrm{Ph}+/-7$ ALL comprised mainly older males with early B-lineage ALL, whose induction failure rate $(3.1 \%)$ was much higher than that among $\mathrm{Ph}$-cases. These findings suggest that leukemic transformation in such patients is a multistep process involving the interaction of a dominant oncogene (Ph; BCR-ABL) with a tumor suppressor gene $(-7)$. In both children and adults, $\mathrm{t}(9 ; 22)$ ALL has the worst prognosis among patients with ALL. Oyekunle et al. have described that the deletions of the IKZF1 gene confer an adverse risk profile in Ph-positive ALL [45]. The IKZF1 gene has a coding function for a transcription regulator involved in T- and B-cell differentiation.

In our study, it was not possible to perform both karyotype and FISH panel for MLL gene in 30 patients due to some reasons. The detection of $M L L$ rearrangements by karyotyping is although sensitive but sometimes problematic, especially, when the $M L L$-rearrangement is a subtle anomaly, and chromosome preparations are of poor quality. The duplications and deletion involving the $M L L$ genes are even more difficult to detect by karyotyping. For translocations detection, irrespective of the translocation partner, FISH is the method of choice [46]. In our study, out of the four patients positive for $M L L$ rearrangements, two patients (50\%) were detected only by FISH analysis. We, therefore, highly recommend the use of FISH for the detection of $M L L$ rearrangements to overcome the shortcomings associated with the karyotyping.

We found that the frequency of $M L L$ rearrangements was up to $13.3 \%$. This was quite high as compared to study carried out by Safaei et al. attributed their low frequency of $1.5 \%$ to the fact that the occurrence of this abnormality is more frequently seen in infants under 1 year 
and secondary ALL [47]. Because our positive sample size was too low, we cannot say for sure whether this was a chance occurrence or not. $M L L$ translocations in ALL are associated with the pre-B-ALL immunophenotype (CD19+/CD10-) and are characterized by a poor prognosis, particularly in infants [48].

\section{Survival analysis}

The estimated OS for the entire series at 5 years was $75 \%$. Advani et al. documented OS, EFS, and DFS at 5 years of $53 \%, 60 \%$, and $49 \%$, respectively, in their study from TMH between 1986 and 1993 [6]. Silverman et al. in a study found that OS and EFS of $88 \pm 2 \%$ and $83 \pm 2 \%$, respectively, with no difference in OS according to standard and highrisk groups [7]. In another study, it was reported that 6 years EFS in cases of M2 or M3 bone marrow at day 33 of induction was only $11 \pm 5 \%$ [49]. Trigg et al. from Children Cancer Study group documented a 10 years OS and EFS of 73\% and 62\%, respectively, between 1983 and 1989 [50]. Horibe et al. from Japan documented 7 years OS end EFS rates of $76 \pm 1.9 \%$ and $61.4 \pm 2.1 \%$, respectively [51]. Shing et al. from Hong Kong documented 7 years OS of $67-80 \%$ depending on the presenting leukocyte count and that the results were comparable to the MRC UKALL X trials [52]. Thus, results from our hospital are significantly comparable to other series from affluent countries.

Leukemia is a disease with heterogeneous causes and with well-defined cytogenetic molecular abnormalities inducing clinical manifestations [53]. Leukemic cells have a very challenging heterogeneous environment with different receptivity to prescribed drug or chemotherapeutic agents [54]. Therefore, accurate diagnosis using molecular cytogenetics and other advanced techniques plays a crucial role in the overall survival of the patient.

This study has some limitations. First, not all children were tested with all diagnostic techniques and therefore, the sample size for comparison between the two techniques, i.e., karyotyping and FISH was quite low. Further studies with increased sample size would be worthwhile to analyze the two techniques. Second, advanced molecular methods to detect subtle abnormalities, including chromosomal microarray, were not available to substantiate our observations. Finally, many patients were lost to follow-up, and therefore, a complete picture of the disease course cannot be said with confidence.

\section{CONCLUSION}

We found that normal karyotypes in our study population were more frequent. Our study indicated that employing FISH technique with increased sensitivity helps in detecting various chromosomal abnormalities, more so with the cryptic rearrangements. Observation of monosomy seven in two out of $B C R-A B L$ positive 5 patients $(40 \%)$ is notable, because the loss of one copy of chromosome seven generally characterizes myeloproliferative disorders that progress to acute myeloid leukemia and suggest that leukemic transformation in such patients is a multistep process involving the interaction of a dominant oncogene (Ph; BCR-ABL) with a tumor suppressor gene $(-7)$. Unlike other studies both in India and in other countries, higher frequency of molecular subgroup of leukemia with a potential for the favorable clinical outcome (ETV6-RUNX1, hyperdiploidy) in precursor B-ALL was observed from the North India. With the availability of NGS and other techniques, we understand the human genome variability and its impact on disease susceptibility and drug response. With the availability of multiple genomic panels for investigation, the whole scenario of diagnosis and decision-making is changing. However, cytogenetics analysis including karyotyping and FISH with clinical details are gold standard, and we recommend their use to provide a more accurate and reliable characterization of ALL for better prognosis and best possible clinical outcome with improved cure rates and decreased drug toxicity.

\section{ACKNOWLEDGMENT}

We greatly acknowledge all the patients who kindly consented to be a part of the study. The authors also thank the whole-hearted support and encouragement from the management of Indraprastha Apollo Hospitals, and Dr. Ashok K Chauhan, Founder President, Amity Group of Institutions.

\section{AUTHORS' CONTRIBUTIONS}

Dr. Mohit Chowdhry, Dr. RN Makroo, and Dr. Pankaj Sharma participated in the conception, design, and coordination of the study; Manoj Kumar, Deepika Rani, and Vandana Sharma performed the study; Manoj Kumar, and Dr. Mohit Chowdhry drafted the manuscript.

\section{CONFLICTS OF INTEREST}

The authors report no conflicts of interest.

\section{REFERENCES}

1. Pui CH, Evans WE. Acute lymphoblastic leukemia. N Engl J Med 1998:339:605-15.

2. Gaynon PS. Childhood acute lymphoblastic leukaemia and relapse. $\mathrm{Br}$ J Haematol 2005;131:579-87.

3. Pui CH, Sandlund JT, Pei D, Rivera GK, Howard SC, Ribeiro RC, et al. Results of therapy for acute lymphoblastic leukemia in black and white children. JAMA 2003;290:2001-7.

4. Advani SH, Rao DN, Gopal R, Nair CN, Battacharya M. Acute lymphoblastic leukemia: End-result analysis of treatment and prognostic factors in Indian patients. Am J Hematol 1983;15:35-43

5. Advani SH, Iyer RS, Pai SK, Gopal R, Saikia TK, Nair CN, et al. Fouragent induction/consolidation therapy for childhood acute lymphoblastic leukemia: An Indian experience. Am J Hematol 1992;39:242-8.

6. Advani S, Pai S, Venzon D, Adde M, Kurkure PK, Nair CN, et al. Acute lymphoblastic leukemia in India: An analysis of prognostic factors using a single treatment regimen. Ann Oncol 1999;10:167-76.

7. Silverman LB, Gelber RD, Dalton VK, Asselin BL, Barr RD, Clavell LA, et al. Improved outcome for children with acute lymphoblastic leukemia: Results of Dana-Farber consortium protocol 91-01. Blood 2001;97:1211-8.

8. Wessels G, Hesseling PB, Buurman M, Oud C, Nel ED. An analysis of prognostic variables in acute lymphocytic leukaemia in a heterogenous South African population. J Trop Pediatr 1997;43:156-61.

9. Shanta V, Maitreyan V, Sagar TG, Gajalakshmi CK, Rajalekshmy KR. Prognostic variables and survival in pediatric acute lymphoblastic leukemias: Cancer institute experience. Pediatr Hematol Oncol 1996;13:205-16.

10. Pui CH, Robison LL, Look AT. Acute lymphoblastic leukaemia. Lancet 2008;371:1030-43

11. Mrózek K, Harper DP, Aplan PD. Cytogenetics and molecular genetics of acute lymphoblastic leukemia. Hematol Oncol Clin North Am 2009;23:991-1010, v.

12. Chessels JM, Swansbury GJ, Reeves B, Bailey CC, Richards SM. Cytogenetics and prognosis in childhood lymphoblastic leukaemia: Results of MRC UKALL X. Medical research council working party in childhood leukaemia. Br J Haematol 1997;99:93-100.

13. Harrison CJ, Moorman AV, Barber KE, Broadfield ZJ, Cheung KL, Harris RL, et al. Interphase molecular cytogenetic screening for chromosomal abnormalities of prognostic significance in childhood acute lymphoblastic leukaemia: A UK cancer cytogenetics group study. Br J Haematol 2005; 129:520-30.

14. Waghray M, Rowley JD, Reddy PP, Reddy SV. A cytogenetic study of children in India with acute lymphocytic leukemia: Correlation with clinical data. Cancer Genet Cytogenet 1986;23:225-37.

15. Yang CP, Wu JH, Hung IJ, Jaing TH. Cytogenetic pattern of childhood leukemia in Taiwan. J Formos Med Assoc 2000;99:281-9.

16. Forestier E, Johansson B, Borgström G, Kerndrup G, Johansson J, Heim S, et al. Cytogenetic findings in a population-based series of 787 childhood acute lymphoblastic leukemias from the Nordic countries. The NOPHO leukemia cytogenetic study group. Eur J Haematol 2000;64:194-200.

17. Pérez-Vera P, Mújica-Sánchez M, Carnevale A, Rivera-Luna R, Paredes R, Martínez A, et al. Cytogenetics in acute lymphoblastic leukemia in Mexican children: An institutional experience. Arch Med Res 2001;32:202-7.

18. Whitlock JA, Gaynon PS. Acute lymphoblastic leukemia in children. In: Greer JP, Foerster J, Rodgers GM, Paraskevas F, Glader B, Arber D, et al, editors. Wintrobe's Clinical Hematology. $12^{\text {th }}$ ed., Vol. 2 . Philadelphia, PA: Lippincott Williams and Wilkins; 2009. p. 1889-910. 
19. Gladstone B, Amare PS, Pai SK, Gopal R, Joshi S, Nair CN, et al. Cytogenetic studies in patients from india with T-acute lymphoblastic leukemia. Cancer Genet Cytogenet 1998;106:44-8.

20. Amare P, Gladstone B, Varghese C, Pai S, Advani S. Clinical significance of cytogenetic findings at diagnosis and in remission in childhood and adult acute lymphoblastic leukemia: Experience from India. Cancer Genet Cytogenet 1999;110:44-53.

21. Li X, Li J, Hu Y, Xie W, Du W, Liu W, et al. A comprehensive cytogenetic classification of 1466 Chinese patients with de novo acute lymphoblastic leukemia. Leuk Res 2012;36:720-6.

22. Aricò M, Valsecchi MG, Rizzari C, Barisone E, Biondi A, Casale F, et al. Long-term results of the AIEOP-ALL-95 trial for childhood acute lymphoblastic leukemia: Insight on the prognostic value of DNA index in the framework of Berlin-Frankfurt-Muenster based chemotherapy. J Clin Oncol 2008;26:283-9.

23. Pedersen-Bjergaard J, Rowley JD. The balanced and the unbalanced chromosome aberrations of acute myeloid leukemia may develop in different ways and may contribute differently to malignant transformation. Blood 1994;83:2780-6.

24. Onodera N, McCabe NR, Rubin CM. Formation of a hyperdiploid karyotype in childhood acute lymphoblastic leukemia. Blood 1992;80:203-8.

25. Onciu M. Acute lymphoblastic leukemia. Hematol Oncol Clin North Am 2009;23:655-74.

26. Pui CH, Carroll AJ, Raimondi SC, Land VJ, Crist WM, Shuster JJ, et al. Clinical presentation, karyotypic characterization, and treatment outcome of childhood acute lymphoblastic leukemia with a nearhaploid or hypodiploid less than 45 line. Blood 1990;75:1170-7.

27. Padhi S, Sarangi R, Mohanty P, Das R, Chakravarty S, Rand M, Jacob RT. Cytogenetic profile of pediatric acute lymphoblastic leukemia (ALL): Analysis of 31 cases with review of literature. Caryologia 2011;64:33-41.

28. Seeger K, von Stackelberg A, Taube T, Buchwald D, Körner G, Suttorp M, et al. Relapse of TEL-AML1 positive acute lymphoblastic leukemia in childhood: A matched-pair analysis. J Clin Oncol 2001;19:3188-93

29. Shurtleff SA, Buijs A, Behm FG, Rubnitz JE, Raimondi SC, Hancock ML, et al. TEL/AML1 fusion resulting from a cryptic $\mathrm{t}(12 ; 21)$ is the most common genetic lesion in pediatric ALL and defines a subgroup of patients with an excellent prognosis. Leukemia 1995;9:1985-9.

30. Romana SP, Poirel H, Leconiat M, Flexor MA, Mauchauffé M, Jonveaux $\mathrm{P}$, et al. High frequency of $\mathrm{t}(12 ; 21)$ in childhood B-lineage acute lymphoblastic leukemia. Blood 1995;86:4263-9.

31. Settin A, Al Haggar M, Al Dosoky T, Al Baz R, Abdelrazik N, Fouda M, et al. Prognostic cytogenetic markers in childhood acute lymphoblastic leukemia. Indian J Pediatr 2007;74:255-63.

32. Yehuda-Gafni O, Cividalli G, Abrahmov A, Weintrob M, Neriah SB, Cohen $\mathrm{R}$, et al. Fluorescence in situ hybridization analysis of the cryptic $\mathrm{t}(12 ; 21)(\mathrm{p} 13 ; \mathrm{q} 22)$ in childhood B-lineage acute lymphoblastic leukemia. Cancer Genet Cytogenet 2002;132:61-4.

33. Inamdar N, Kumar SA, Banavali SD, Advani S, Magrath I, Bhatia K, et al. Comparative incidence of the rearrangements of TEL/AML1 and ALL1 genes in pediatric precursor B acute lymphoblastic leukemias in India. Int J Oncol 1998;13:1319-22.

34. Jiménez-Morales S, Miranda-Peralta E, Saldaña-Alvarez Y, Perez-Vera P, Paredes-Aguilera R, Rivera-Luna R, et al. BCR-ABL, ETV6-RUNX1 and E2A-PBX1: Prevalence of the most common acute lymphoblastic leukemia fusion genes in Mexican patients. Leuk Res 2008;32:1518-22.

35. Alonso CN, Gallego MS, Alfaro EM, Rossi JG. Caracterizacion molecular en leukemia linfoblastica aguda pediatrica en una institucion hospitalaria. Pediatric lymphoblastic leukemia molecular characterization in a single institution. Hematologica 2006;10:8-12.
36. Tiensiwakul P. Cloning and sequencing of ETV6/RUNX1 (TEL/AML1) variant in acute lymphoblastic leukemia. Cancer Genet Cytogenet 2004;149:85-8.

37. Tsang KS, Li CK, Chik KW, Shing MM, Tsoi WC, Ng MH, et al. TEL/AML1 rearrangement and the prognostic significance in childhood acute lymphoblastic leukemia in Hong Kong. Am J Hematol 2001;68:91-8.

38. Liang DC, Chou TB, Chen JS, Shurtleff SA, Rubnitz JE, Downing JR, et al. High incidence of TEL/AML1 fusion resulting from a cryptic $\mathrm{t}(12 ; 21)$ in childhood B-lineage acute lymphoblastic leukemia in Taiwan. Leukemia 1996;10:991-3.

39. Khan AA, Jameel T, Anwar M. Chromosomal changes in acute lymphoblastic leukemia. Pakistan J Pathol 1999;10:26-9.

40. Khalid S, Usman M, Adil SN, Ayub A, Khurshid M. Pattern of chromosomal abnormalities in adult acute lymphoblastic leukemia. Indian J Pathol Microbiol 2007;50:78-81.

41. Crist W, Carroll A, Shuster J, Jackson J, Head D, Borowitz M, et al. Philadelphia chromosome positive childhood acute lymphoblastic leukemia: Clinical and cytogenetic characteristics and treatment outcome. A pediatric oncology group study. Blood 1990;76:489-94.

42. Chan LC, Kwong YL, Liu HW, Chan TK, Todd D, Ching LM, et al. Cytogenetic analysis of hematologic malignancies in Hong Kong. A study of 98 cases. Cancer Genet Cytogenet 1992;62:154-9.

43. Fletcher JA, Lynch EA, Kimball VM, Donnelly M, Tantravahi R, Sallan SE, et al. Translocation $(9 ; 22)$ is associated with extremely poor prognosis in intensively treated children with acute lymphoblastic leukemia. Blood 1991;77:435-9.

44. Russo C, Carroll A, Kohler S, Borowitz M, Amylon M, Homans A, et al. Philadelphia chromosome and monosomy 7 in childhood acute lymphoblastic leukemia: A Pediatric oncology group study. Blood 1991;77:1050-6.

45. Oyekunle A, Haferlach T, Kröger N, Klyuchnikov E, Zander AR, Schnittger S, Bacher U. Molecular diagnostics, targeted therapy, and the indication for allogeneic stemcell transplantation in acute lymphoblastic leukemia. Adv Hematol 2011;2011:154745.

46. Olde Nordkamp L, Mellink C, van der Schoot E, van den Berg H. Karyotyping, FISH, and PCR in acute lymphoblastic leukemia: Competing or complementary diagnostics? J Pediatr Hematol Oncol 2009;31:930-5.

47. Safaei A, Shahryari J, Farzaneh MR, Tabibi N, Hosseini M. Cytogenetic findings of patients with acute lymphoblastic leukemia in Fars province. Iran J Med Sci 2013;38:301-7.

48. Pui CH, Chessells JM, Camitta B, Baruchel A, Biondi A, Boyett JM, et al. Clinical heterogeneity in childhood acute lymphoblastic leukemia with 11q23 rearrangements. Leukemia 2003;17:700-6.

49. Schrappe M. Prognostic factors in childhood acute lymphoblastic leukemia. Indian J Pediatr 2003;70:817-24.

50. Trigg ME, Sather HN, Reaman GH, Tubergen DG, Steinherz PG, Gaynon PS, et al. Ten-year survival of children with acute lymphoblastic leukemia: A report from the children's oncology group. Leuk Lymphoma 2008;49:1142-54.

51. Horibe K, Hara J, Yagi K, Tawa A, Komada Y, Oda M, et al. Prognostic factors in childhood acute lymphoblastic leukemia in Japan. Japan association of childhood leukemia study. Int J Hematol 2000;72:61-8.

52. Shing MM, Li CK, Chik KW, Lam TK, Lai HD, Ng MH, et al. Outcomes and prognostic factors of Chinese children with acute lymphoblastic leukemia in Hong Kong: Preliminary results. Med Pediatr Oncol 1999:32:117-23.

53. Darji AA, Bharadia PD. Chronic myelogenous leukemia: A review and update of current and future therapy. Int J Pharm Pharm Sci 2016;8:3546.

54. Gupta M, Dahiya J, Marwaha RK, Dureja H. Therapies in cancer treatment. An overview. Int J Pharm Pharm Sci 2015;7:1-9. 